\title{
Stream habitat structure influences macroinvertebrate response to pesticides
}

\author{
Jes Jessen Rasmussen*, Peter Wiberg-Larsen, Annette Baattrup-Pedersen, Nikolai Friberg, Brian Kronvang \\ Aarhus University, Department of Bioscience, Vejlsøvej 25, 8600 Silkeborg, Denmark
}

\section{A R T I C L E I N F O}

\section{Article history:}

Received 9 November 2011

Received in revised form

4 January 2012

Accepted 8 January 2012

\section{Keywords:}

Macroinvertebrates

SPEAR

Pesticide stress

Physical habitats

Multiple stressors

Risk assessment

\begin{abstract}
A B S T R A C T
Agricultural pesticides continue to impair surface water ecosystems, although there are few assessments of interactions with other modifications such as fine sediment and physical alteration for flood drainage. We, therefore, surveyed pesticide contamination and macroinvertebrates in 14 streams along a gradient of expected pesticide exposure using a paired-reach approach to differentiate effects between physically modified and less modified sites. Apparent pesticides effects on the relative abundance of SPEcies At Risk (SPEAR) were increased at sites with degraded habitats primarily due to the absence of species with specific preferences for hard substrates. Our findings highlight the importance of physical habitat degradation in the assessment and mitigation of pesticide risk in agricultural streams.
\end{abstract}

(c) 2012 Elsevier Ltd. All rights reserved.

\section{Introduction}

Ecology is being increasingly integrated into ecotoxicology to improve the understanding of how contaminants impact natural ecosystems. This interest has been particularly strong in aquatic ecosystems with a special emphasis on the non-target effects of pesticides (Liess et al., 2005; Relyea and Hoverman, 2006). In these same systems, the use of biological traits to appraise the effects of natural disturbances on macroinvertebrate communities is probably more advanced than in any other system (Paillex et al., 2009; Townsend and Hildrew, 1994; Townsend et al., 2008), and this approach is considered promising for the detection and interpretation of the impact of pesticides (Baird et al., 2011).

The distribution and abundance of specific traits of lotic macroinvertebrates are remarkably constant among similar types of ecosystems - even across biogeoregions - whereas the species composition is much more variable (Baird and Van den Brink, 2007; Rubach et al., 2011). Moreover, biological traits respond quite specifically to certain sources of anthropogenic stress such as land use (Doledec et al., 2006), sewage effluents (Statzner et al., 2001) and the periodic exposure of agricultural pesticides (Liess and Von der Ohe, 2005; Rubach et al., 2010) making the trait approach potentially extremely valuable in assessing the effects of multiple stressors that frequently co-occur in stream ecosystems.

\footnotetext{
* Corresponding author.

E-mail address: jr@dmu.dk (J.J. Rasmussen).
}

One example of the assessment of ecological risk using biological traits is the SPEcies At Risk index (SPEAR) which is an ecological indicator system that is based on the biological traits of lotic and lentic macroinvertebrates (Liess and Von der Ohe, 2005). The SPEAR index applies physiological (sensitivity to pesticides and other organic toxicants) and biological (generation time, timing and duration of terrestrial life stages and dispersal capacity) traits to determine the relative abundance of the species that are at risk of being impacted by the periodic exposure of pesticides. The SPEAR indicator has been demonstrated to remain relatively constant among reference stream ecosystems and, more importantly it responds selectively to pesticide stress in small streams across different biogeoregions (Beketov and Liess, 2008; Liess and Von der Ohe, 2005; Schäfer et al., 2007, 2011).

However, in spite of the clear strength in using biological traits for risk assessment such as SPEAR, the potential interaction of different anthropogenic stressors may prompt altered effects (Matthaei et al., 2010; Rasmussen et al., 2011a; Wagenhoff et al., 2011). As the effect of one stressor may reduce the fitness of an organism, the effect of another stressor may increase. Conversely, the effect of one stressor may result in competitive release for one organism (e.g. elimination of predators) increasing its fitness and potentially reducing its sensitivity to other stressors (Pedersen and Friberg, 2009). One such potential stressor that often interacts with the presence of pesticides in agricultural areas is the intensive maintenance of streams by channelisation and dredging, used to maximise flow conveyance into the stream channel and along it. One side-effect of the maintenance activities is a severe 
degradation of the diversity and quality of physical habitats in the streams. The physical structure of heavily maintained streams is often characterised by higher proportions of soft substrates and low variability in depth and width of the streams (Pedersen, 2009). In addition, the degradation of physical habitats results in more laminar and in general slower flow which reduces the reaeration capacity and periodically the total oxygen content in the stream water (Friberg et al., 2009; Pedersen, 2009).

Significant variation in the community structure of benthic macroinvertebrates has been ascribed to substrate characteristics (e.g. particle size) and habitat heterogeneity (Brunke et al., 2001; Pedersen and Friberg, 2009). Many lotic Ephemeroptera, Plecoptera and Trichoptera (EPT) require high current velocities, well oxygenated water and coarse substrate (Giller and Malmqvist, 1998), and moreover many EPT taxa have narrower niche requirements than taxa related to physically uniform streams with soft sediments (Dunbar et al., 2010). Therefore, high habitat heterogeneity is essential if the site is to support a larger proportion of the EPT taxa. The majority of EPT species are additionally characterised as at risk in the SPEAR index (Liess and Von der Ohe, 2005). In consequence, the species pool of potential macroinvertebrate colonisers is severely reduced for reaches with degraded physical conditions - and/or resident species may additionally experience increasing sensitivity to pollutants due to suboptimal physical conditions at the level of micro-habitats. In consequence, both of these factors could influence the outcome of the SPEAR index as previously insinuated by Rasmussen et al. (2011a) and Schletterer et al. (2010). Riffle sections of streams have been prioritised for macroinvertebrate sampling in previous studies using the SPEAR index (Liess and Von der Ohe, 2005; Schletterer et al., 2010; Schäfer et al., 2007, 2011; von der Ohe et al.,
2007). To our knowledge studies that address pesticide effects on conjunction with channel modifications have not been conducted before.

The principal aim of this study was to investigate the relationship between pesticide contamination and macroinvertebrate community composition in streams with differing structure and diversity of physical micro-habitats. We sampled 14 Danish 1st and 2nd order streams in each of which two reaches with differing physical habitat characteristics were selected. We used this set-up to test the hypotheses that 1) the fraction of SPEcies At Risk (SPEAR) is lower at reaches that are characterised by degraded physical habitats compared to reaches with more unmodified habitats due to especially the preference for hard substrate for many EPT taxa, and 2) the reduction of the fraction of SPEAR during the main pesticide application season is higher at sites that are characterised by degraded habitats as a consequence of increased multiplicative stress.

\section{Methods}

\subsection{Study design}

The field campaign was conducted in 2009 in 14 1st and 2nd order streams located on Funen, Denmark. The region is dominated by agriculture and the study catchments are characterised by low elevation and loamy/clayey soils (Fig. 1). Rye, wheat, barley, grass and oilseed rape were the dominating crop types (see also Rasmussen et al., 2011b). Of all pesticides that were expected to be applied onto the fields, $48 \%$ were herbicides, $28 \%$ were fungicides (primarily boscalid and triazole compounds) and 24\% were insecticides (mainly pyrethroids) (Danish EPA, 2010).

The study streams were selected based on the following criteria: 1) year-round water flow, 2) no physical maintenance activities during the sampling period, and 3) no sources of pollution other than those originating from normal agricultural practices. The streams were selected to exhibit a gradient of agricultural pressure and potential exposure to agricultural pesticides (predicted from the proportion of adjacent agricultural land).

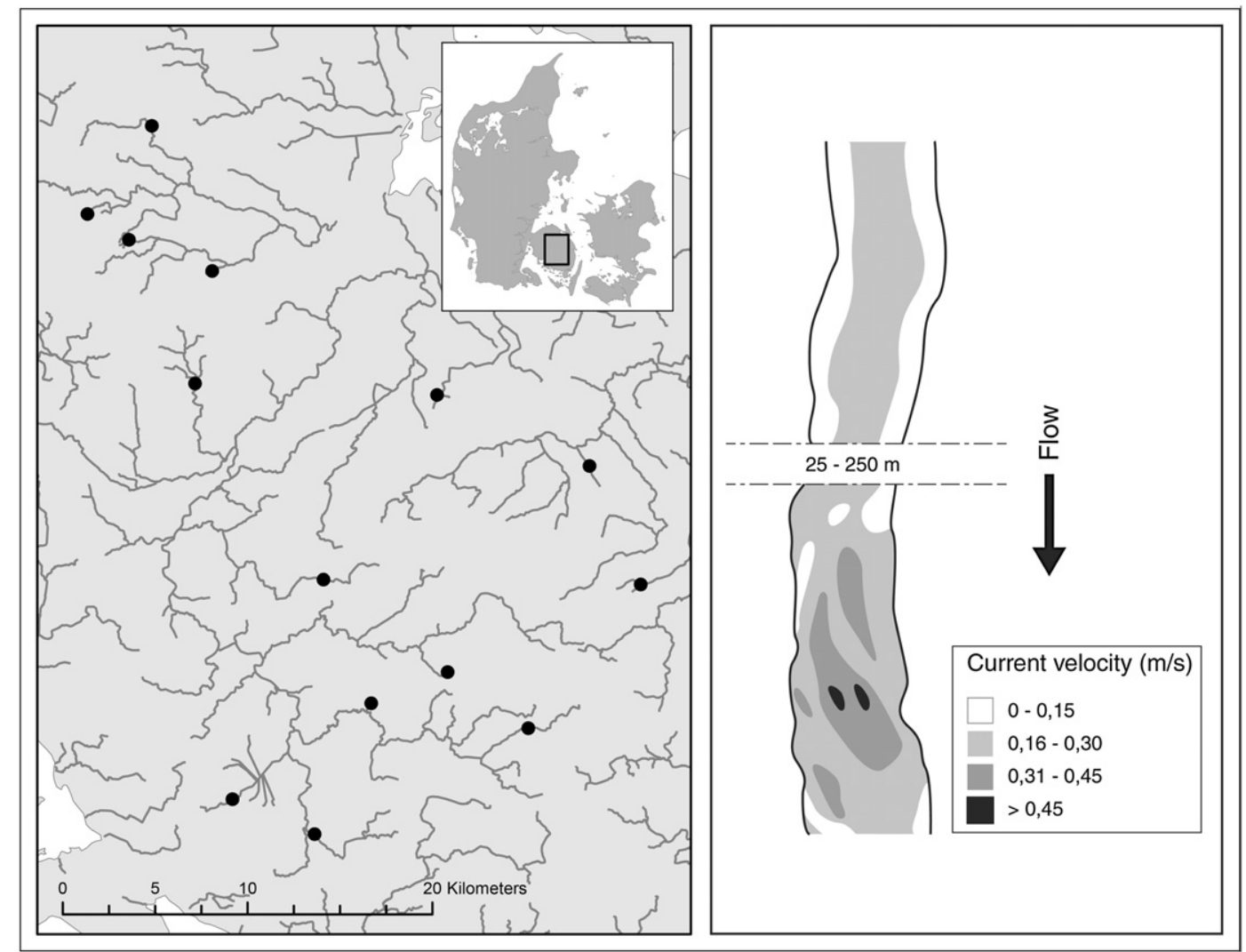

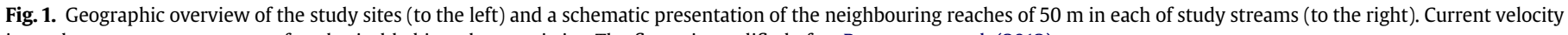
is used as a surrogate measure for physical habitat characteristics. The figure is modified after Rasmussen et al. (2012). 
In each study stream, two reaches of $50 \mathrm{~m}$ were selected based on the physical and hydromorphological properties of the reach (Fig. 1). The selection criteria for the reaches were 1) presence of an upstream reach characterised by low current velocity, low physical diversity and low reaeration capacity; 2) a downstream reach characterised by fast flow, high physical diversity and high reaeration capacity, and 3 ) the distance between reaches should not exceed $250 \mathrm{~m}$ in order to maximise the similarity of water chemistry between reaches. For convenience reaches are referred to as sampling sites in the succeeding parts of the article.

\subsection{Pesticide monitoring and water chemistry}

A total of 19 herbicides, 6 fungicides and 6 insecticides were monitored representing some of the most frequently applied compounds in Danish agriculture along with presently banned compounds that are commonly found in groundwater magazines (Supplementary material A). Pesticides were sampled with eventtriggered samplers (Liess and Von der Ohe, 2005) during the spraying season (May and June) and additional water samples were collected manually in August during low flow to characterise the pesticide contamination that originates from groundwater inflow. Two major precipitation events triggered some (the 28th of May) or all (the 12th of June) event-triggered samplers. A detailed overview of the sampling methods, chemical analysis methods and detected pesticide compounds are described elsewhere (Rasmussen et al., 2011b, 2012).

To compare the potential impact of pesticides on macroinvertebrates among streams, the measured pesticide concentrations were used to calculate the log maximum Toxic Unit (mTU) of all compounds detected in each sample. According to Tomlin (2000) the calculated log TU for each compound was based on the standard 48-h acute LC50 value for Daphnia magna:

$\log \mathrm{TU}_{D . \text { magna }}=\log \left(C_{i} / \mathrm{LC} 0_{i}\right)$

where $\log \mathrm{TU}_{D \text {. magna }}$ is the toxic unit for pesticide $i, C_{i}$ is the measured concentration of the pesticide $i$ and $\mathrm{LC} \mathrm{O}_{i}$ is the corresponding 48-h LC50 value for $D$. magna exposed to the pesticide $i$.

Water samples for general chemistry were collected manually in April, June and August (Table 1). The BOD $_{5}$, ortho-phosphate and ammonia-N were analysed according to European Standards (DS/EN 1899 1999, DS/EN 1189-1997 and DS 11732 2005, respectively). Nitrate-N was analysed using Lachat-methods (Lachat Instruments, USA, Quickchem. No. 10-107-06-33-A (Salycate method)). Concentrations of total $\mathrm{N}$ and total $\mathrm{P}$ were measured (unfiltered samples) applying the Kjeldahl-N method (Kjeldahl, 1883) and Danish standard (DS-291), respectively.

\subsection{Physical properties}

For each of the sampling sites twenty-five transects were established with two meter intervals. Results from the physical surveys are presented in Table 1 and in further detail in Rasmussen et al. (2012). Stream width, $(W)$, depth $(D)$ and water

\section{Table 1}

Physical and chemical characteristics for two sites in each of 14 streams. The upstream site was characterised by homogenous and heavily modified physical properties, and the downstream site was characterised by more diverse and unmodified physical properties. Values represent the average $( \pm \mathrm{SE})$ of three surveys conducted in April, June and August, 2009.

\begin{tabular}{|c|c|c|}
\hline Parameter & $\begin{array}{l}\text { Reaches with } \\
\text { heterogeneous } \\
\text { physical conditions }\end{array}$ & $\begin{array}{l}\text { Reaches with } \\
\text { homogenous } \\
\text { physical conditions }\end{array}$ \\
\hline Discharge ( $\mathrm{L} \mathrm{s}^{-1}$ ) & $4.7 \pm 0.3$ & $2.8 \pm 0.2$ \\
\hline Shear stress & $6.5 \pm 0.3$ & $5.5 \pm 0.2$ \\
\hline Width (m) & $1.27 \pm 0.02$ & $1.4 \pm 0.01$ \\
\hline Depth (m) & $0.05 \pm 0.01$ & $0.10 \pm 0.01$ \\
\hline Cobble (\%) & $14.2 \pm 0.6$ & $4.0 \pm 0.4$ \\
\hline Gravel (\%) & $42.8 \pm 1.2$ & $10.7 \pm 1.9$ \\
\hline Sand (\%) & $18.1 \pm 0.6$ & $24.5 \pm 1.4$ \\
\hline Silt (\%) & $16.3 \pm 0.4$ & $50.1 \pm 1.6$ \\
\hline Debris (\%) & $6.1 \pm 0.4$ & $8.4 \pm 0.7$ \\
\hline $\begin{array}{l}\text { \# Submergent } \\
\text { macrophyte species }\end{array}$ & $0.7 \pm 0.0$ & $0.9 \pm 0.1$ \\
\hline $\begin{array}{l}\text { Total macrophyte } \\
\text { coverage }(\%)\end{array}$ & $13.4 \pm 1.3$ & $22.3 \pm 0.8$ \\
\hline Temperature $\left({ }^{\circ} \mathrm{C}\right)$ & $11.3 \pm 0.4$ & $14.2 \pm 0.8$ \\
\hline $\mathrm{BOD}_{5}\left(\mathrm{mg} \mathrm{L}^{-1}\right)$ & $1.90 \pm 0.1$ & $1.98 \pm 0.1$ \\
\hline Oxygen concentration $\left(\mathrm{mg} \mathrm{L}^{-1}\right)$ & $8.67 \pm 0.4$ & $8.32 \pm 0.7$ \\
\hline Ammonia $\left(\mathrm{mg} \mathrm{L}^{-1}\right)$ & $0.07 \pm 0.01$ & $0.06 \pm 0.01$ \\
\hline Nitrate $\left(\mathrm{mg} \mathrm{L}^{-1}\right)$ & $2.21 \pm 0.12$ & $2.29 \pm 0.11$ \\
\hline Total $\mathrm{N}\left(\mathrm{mg} \mathrm{L}^{-1}\right)$ & $2.91 \pm 0.12$ & $2.79 \pm 0.12$ \\
\hline Ortho-Phosphate ( $\mathrm{mg} \mathrm{L}^{-1}$ ) & $0.07 \pm 0.00$ & $0.06 \pm 0.00$ \\
\hline Total $\mathrm{P}\left(\mathrm{mg} \mathrm{L}^{-1}\right)$ & $0.13 \pm 0.00$ & $0.16 \pm 0.01$ \\
\hline
\end{tabular}

velocity $(0.4 \times$ depth from the stream bed) $(U)$ were measured at four points along each transect corresponding to $25,50,75$ and $100 \%$ of the wetted width. Current velocity was measured using a flow-meter (Höntzsch $\mu$ P-TAD). The discharge was calculated from average stream dimensions and average current velocity. Furthermore, four rectangular plots were established between each pair of transects $(2 \mathrm{~m} \times 25 \%$ of the stream width). Substrate types and macrophyte coverage were quantified in each plot, and submergent and emergent macrophytes were identified to the lowest possible taxonomical level. The proportional coverage for each taxon was also quantified. Stream water temperature, conductivity and oxygen concentration were registered using a multi-meter (WTW multi-350i) and $\mathrm{pH}$ was measured with a (YSI-60) pH-meter.

\subsection{Macroinvertebrates}

Macroinvertebrates were sampled in April, June and August, 2009 using a surber sampler $\left(200 \mathrm{~cm}^{2}\right)$ (Supplementary material B). Five surber samples were collected from each site according to a predefined randomised sampling approach and samples were preserved in $70 \%$ ethanol in the field. All macroinvertebrates were counted and identified to the level of species or genus, except Chironomidae (subfamily), Simuliidae (family), Oligochaeta (order). In addition, \%SPEAR abundance was computed for each of the sites and sampling months using the freely available online SPEAR calculator (http://www.systemecology.eu/SPEAR/index.php).

\subsection{Data analysis}

Applying a principal component analysis (PCA) the two most important stressors were identified in a companion paper (Rasmussen et al., 2012) with one being characterised by land-use intensity and $\log \mathrm{mTU}_{\text {D.magna }}$ and the other being characterised by substrate characteristics (relative coverage of boulders, gravel and silt).

Separate linear regressions were performed for the two site categories (homogeneous and heterogeneous physical conditions) on the relationship between $\log \mathrm{mTU}_{D}$. magna and \%SPEAR abundance and the relationship between the log $\mathrm{mTU}_{D \text {.magna }}$ and ${ }_{\text {\%SPEAR }}$ mod abundance. We used Analysis of Covariance (ANCOVA) to test for differences in slopes and intercepts between regression lines $(P<0.05)$ applying the software SAS 9.1 .

We used the method from Dufrêne and Legendre (1997) to calculate indicator values for all taxa that were detected in June samples in order to characterise the probability for a taxon to occur in a certain habitat type. A significance threshold of 0.1 was applied to promote the most overall trends. The series of permutations were performed distinguishing between a) sites with homogeneous and heterogeneous physical conditions. The indicator values were tested for statistical significance using a Monte Carlo technique, and the analyses were performed using PCOrd 4 . The level of genus was applied for the caddisflies belonging to the genus Silo, since the two species that were found in the study streams (Silo palipes and Silo nigricornis) have similar preferences for habitats with coarse substrate (Wallace et al., 2003). We additionally calculated a modified \%SPEAR abundance $\left(\mathrm{SPEAR}_{\mathrm{mod}}\right)$ excluding the species that were found to be characteristic for reaches with heterogeneous physical conditions in order to evaluate if these taxa were the primary reason for lower \% SPEAR abundance at sites with homogenous physical conditions. In addition, we calculated the \%SPEAR abundance only using taxa belonging to Ephemeroptera, Plecoptera and Trichoptera (EPT) or only using the taxa that did not belong to EPT (SPEAR $_{\text {EPT }}$ and SPEAR in \%SPEAR abundance between site types was governed by SPEAR taxa belonging or not belonging to EPT. The SPEAR mod, SPEAR $_{\text {EPT }}$ and SPEAR notEPT $_{\text {were calculated }}$ using the SPEAR classification from Liess and Von der Ohe (2005).

Lastly, we grouped the sites according to their physical conditions (homogeneous and heterogeneous) and the measured toxicity of pesticides during storm flow (TU $\leq-5,-5<\mathrm{TU} \leq-3$ and $\mathrm{TU}>-3$ ). The temporal development from April to August in average \%SPEAR abundance, \%SPEAR EPT $_{\text {abundance and } \% \text { SPEAR }}$ notEPT abundance were compared for each of the six site groups $(P<0.05)$. Moreover, we compared the average \%SPEAR abundance between the site groups for each of the months April, June and August.

Lastly, we compared the average difference in \%SPEAR abundance between the sites with heterogeneous and homogeneous physical properties among the site groups $(\mathrm{TU} \leq-5,-5<\mathrm{TU} \leq-3$ and $\mathrm{TU}>-3$, representing unimpacted, moderately and heavily impacted streams, respectively) for each of the months April, June and August using one way analysis of variance. In the case of significant differences among groups $(P<0.05$, ANOVA) a Bonferroni $t$-test was used as post hoc test to evaluate pairwise differences. The ANOVAS were performed using SAS Enterprise Guide 4.2.

\section{Results}

\subsection{Physical habitat properties and SPEAR}

The $\log \mathrm{mTU}_{D \text {. magna }}$ was consistently higher for runoff-related water samples compared to base-flow water samples. The 
pesticide compounds causing the $\log \mathrm{mTU}_{D}$. magna in storm flow water samples differed along the gradient of agricultural intensity in the catchment (Table 2).

The $\log \mathrm{mTU}_{D}$. magna explained a significant proportion of the variation in \%SPEAR abundance in April, June and August for sites with homogeneous $\left(R^{2}=0.60, P<0.001 ; R^{2}=0.60, P<0.001\right.$; $\left.R^{2}=0.61, P<0.001\right)$ and heterogeneous physical properties $\left(R^{2}=0.41, P<0.05 ; R^{2}=0.68, P<0.001 ; R^{2}=0.40, P<0.05\right)$ (Fig. 2). Slopes of the regression lines for heterogeneous and homogenous sites in April, June and August were not significantly different, whereas the intercepts were significantly different in June $(P<0.05)$ but not in April and August (Fig. 2).

Since the regression lines characterising the correlation between $\log \mathrm{mTU}_{D}$. magna and \%SPEAR abundance were only significantly different between site groups in June, the subsequent analyses for indicator taxa were only conducted for June data. In June three taxa were significant indicators for sites with homogeneous physical conditions and seven taxa were significant indicators for sites with heterogeneous physical conditions $(P<0.1)$ (Table 3). Fully detailed results of the analyses for indicator taxa can be found in the Supplementary material C. Three of the indicator taxa for heterogeneous physical conditions are additionally ranked as SPEcies At Risk (Dicranota sp., Leuctra fusca and Silo spp.) in the SPEAR classification (Liess and Von der Ohe, 2005). Removing these three taxa from the June taxa list, we re-calculated the \%SPEAR

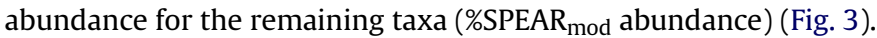

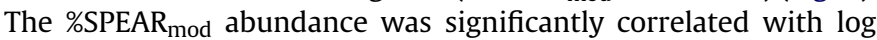
$\mathrm{mTU}_{D . \text { magna }}$ for sites with heterogeneous $\left(R^{2}=0.61, P<0.001\right)$ and homogeneous physical conditions $\left(R^{2}=0.55, P<0.001\right)$. The slopes and intercepts of the regression lines representing sites with heterogeneous and homogeneous physical conditions, respectively, were not significantly different $(P>0.05)$.

\subsection{Temporal analysis of macroinvertebrate community dynamics}

Grouping sites according to their physical conditions (heterogeneous and homogeneous) and the measured $\log \mathrm{mTU}_{D}$. magna (unimpacted ( $\log \mathrm{mTU}_{D}$. magna $<-5$ ), moderately impacted $\left(-5 \leq \log \mathrm{mTU}_{D .}\right.$ magna $\left.<-3\right)$ and heavily impacted $\left(\log \mathrm{mTU}_{D}\right.$. magna $\geq-3)$ ) we found that the average \%SPEAR abundance decreased significantly from April to June in unimpacted streams with homogeneous physical conditions $(P<0.05)$ (Fig. 4A). No significant temporal changes of \%SPEAR abundance were observed

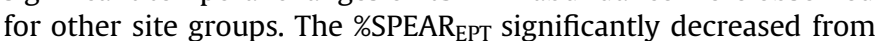

Table 2

The proportion of agriculture in the catchment, log $\mathrm{mTU}_{D \text {. magna }}$ measured in stream water during two heavy precipitation episodes in May and June, 2009 and the compound causing the $\log \mathrm{mTU}_{D}$. magna is presented for each of 14 Danish streams. Samples with no pesticide content are indicated as n.d.

\begin{tabular}{lllll}
\hline Site & $\begin{array}{l}\text { log } \mathrm{mTU}_{D .} \text { magna } \\
\text { Agriculture }\end{array}$ & $\begin{array}{l}\text { log } \mathrm{mTU}_{D .} \text { magna } \\
\text { in runoff } \\
\text { event \#1 }\end{array}$ & $\begin{array}{l}\text { Compound } \\
\text { event \#2 }\end{array}$ & \\
\hline R1 & 2.2 & -6.32 & -6.32 & Desethylterbutylazine (H) \\
R2 & 3.0 & n.d. & -6.63 & Desethylterbutylazine (H) \\
R3 & 2.2 & -6.32 & -6.15 & Desethylterbutylazine (H) \\
R4 & 2.8 & n.d. & -6.23 & Desethylterbutylazine (H) \\
R5 & 15.0 & n.d. & -6.45 & Desethylterbutylazine (H) \\
A1 & 58.0 & n.d. & -4.95 & Boscalid (F) \\
A2 & 58.8 & -5.14 & -4.15 & Pendimethaline (H) \\
A3 & 80.6 & -2.79 & -2.79 & Azoxystrobin (F) \\
A4 & 94.5 & -3.23 & -2.92 & Azoxystrobin (F) \\
A5 & 83.7 & -1.87 & -1.72 & Pirimicarb (I) \\
A6 & 98.8 & -3.41 & -2.73 & Pirimicarb (I) \\
A7 & 87.4 & -3.38 & -3.32 & Azoxystrobin (F) \\
A8 & 54.4 & -3.41 & -3.18 & Azoxystrobin (F) \\
A9 & 84.1 & -3.13 & -2.45 & Pirimicarb (I) \\
\hline
\end{tabular}

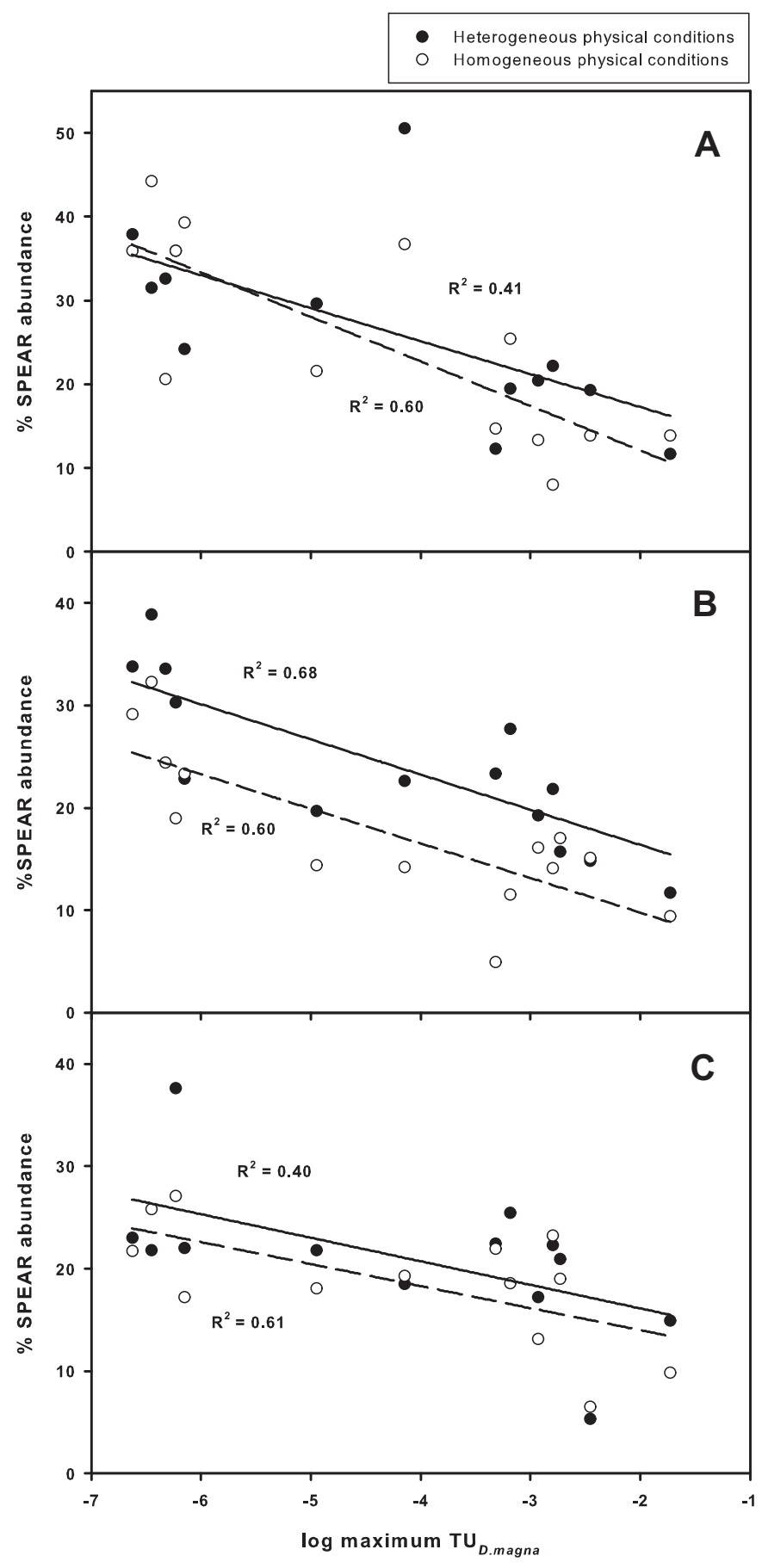

Fig. 2. \%SPEAR abundance as a function of the log maximum $T U_{D}$. magna. SPEAR calculations are based on macroinvertebrate samples collected before (A), during (B) and after $(C)$ the main spraying season of agricultural insecticides. The log maximum $\mathrm{TU}_{D \text {. magna }}$ is based on measured pesticide concentrations during one of two heavy precipitation events in May and June. Regression lines indicate the linear correlations of data points that represent sites with heterogeneous (solid line) and homogeneous (dashed line) physical properties.

April to June in unimpacted stream sites with homogeneous physical conditions $(P<0.05)$ (Fig. 4B). No significant temporal

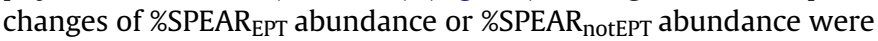
observed for other site groups between either of the months $(P>0.05)$ (Fig. 4B, C).

In April the average \%SPEAR abundance was significantly higher for unimpacted streams than for heavily contaminated streams and for the intermediately contaminated stream sites with 
Table 3

List of taxon groups that were found to be significant indicators for sites with homogeneous or heterogeneous physical conditions. Silo sp. represents the two Danish species of the genus: Silo pallipes and Silo nigricornis. P-values indicate the level of significance for the MONTE CARLO test of the observed maximum indicator value.

\begin{tabular}{lll}
\hline Taxa & Physical indicator group & $P$-value \\
\hline Asellus aquaticus & Homogeneous & 0.048 \\
Baetis rhodani & Heterogeneous & 0.063 \\
Dicranota sp. & Heterogeneous & 0.034 \\
Dugesia gonocephala & Heterogeneous & 0.070 \\
Leuctra fusca & Heterogeneous & 0.083 \\
Limnius volckmari & Heterogeneous & 0.070 \\
Pisidium sp. & Homogeneous & 0.077 \\
Silo spp. & Heterogeneous & 0.010 \\
Simuliidae & Heterogeneous & 0.013 \\
Tanytarsini & Homogeneous & 0.087 \\
\hline
\end{tabular}

homogeneous physical conditions $(P<0.05)$ (Fig. 4A). In June the average \%SPEAR abundance for intermediately and heavily contaminated streams were significantly lower than unimpacted stream sites with heterogeneous physical conditions. Furthermore, the average \%SPEAR abundance for unimpacted stream sites with homogeneous physical conditions and intermediately contaminated stream sites with heterogeneous physical conditions were significantly higher than the average \%SPEAR abundance for intermediately contaminated stream sites with homogeneous physical conditions and heavily contaminated streams. In addition, the \% SPEAR $_{\mathrm{EPT}}$ abundance for intermediately contaminated stream sites with heterogeneous physical conditions was significantly higher than intermediately contaminated sites with homogeneous physical conditions. Other pairwise comparisons (between site groups) of the average \%SPEAR, \%SPEAR EPT $_{\text {and } \% S P E A R}$ notEPT abundance within separate time intervals were not significantly different $(P>0.05)$.

In June the difference in \%SPEAR abundance between sites with heterogeneous and homogeneous physical conditions was significantly greater for intermediately contaminated streams compared to heavily contaminated streams $(P<0.05$, One-way ANOVA $P=0.033$ ). The difference in \%SPEAR abundance between sites with heterogeneous and homogeneous physical conditions for uncontaminated streams was not significantly different from the

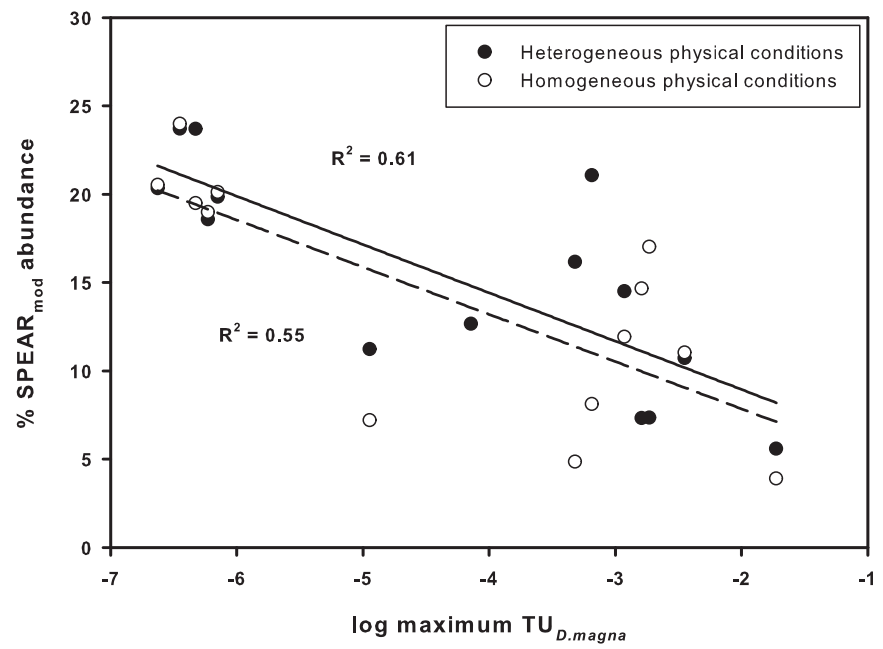

Fig. 3. $\% S P E A R_{\text {mod }}$ abundance as a function of the log maximum $T_{D}$ magna. SPEAR calculations are based on macroinvertebrate data collected in June during the main insecticide spraying season. The log maximum $\mathrm{TU}_{D}$. magna is based on measured pesticide concentrations during heavy precipitation events in May and June. Regression lines indicate the linear correlations of data points that represent sites with heterogeneous (solid line) or homogeneous (dashed line) physical properties.
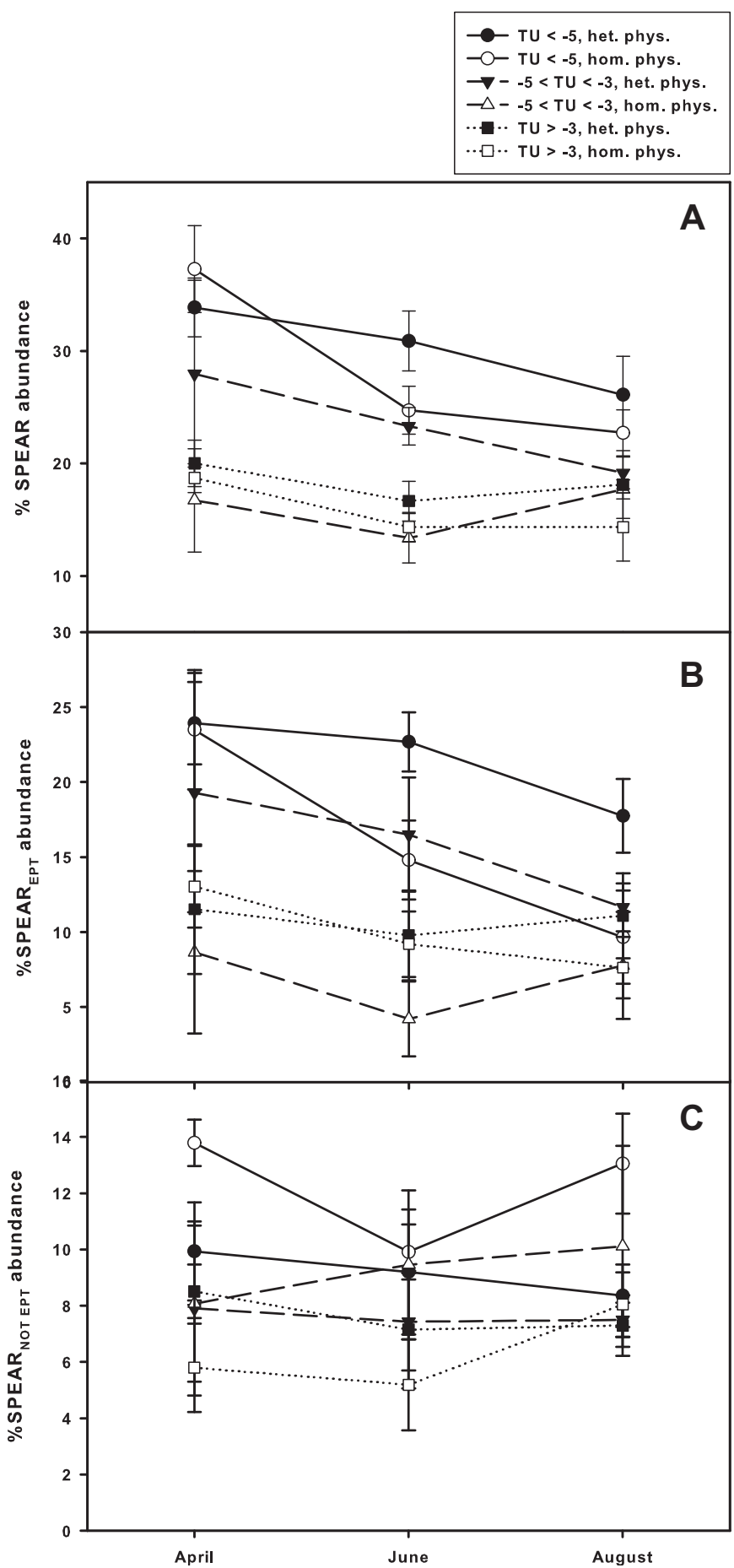

Fig. 4. Average \%SPEAR abundance (A), relative abundance of the SPEAR taxa that belong to EPT (B) and relative abundance of the SPEAR taxa that do not belong to EPT (C) before (April), during (June) and after (August) the main spraying season. Data represents fourteen pairs of stream sites that were characterised by heterogeneous and homogeneous physical conditions, respectively. The stream sites are grouped according to the physical conditions and measured $\log \mathrm{mTU}_{D}$. magna. Error bars indicate SE.

difference in \%SPEAR abundance between sites with heterogeneous and homogeneous physical conditions for the intermediately or heavily contaminated streams (Supplementary material D). The difference in \%SPEAR abundance between sites with heterogeneous and homogeneous physical conditions was not significantly different among site categories in April or August $(P>0.05)$ (Supplementary material D). 


\section{Discussion}

The relative abundance of SPEcies At Risk (SPEAR) during the main pesticide application season (June) was significantly lower at stream sites characterised by uniform and degraded physical habitats compared with sites characterised by more undisturbed and heterogeneous physical habitats. This may reflect that macroinvertebrates residing in micro-habitats with soft substrate and slow flow are subject to increased pressure from multiplicative stressors (e.g. decreased boundary layers, increased amplitude in dissolved oxygen concentrations and low substrate stability) potentially increasing their susceptibility to pesticide contamination (Maltby, 1999; Pedersen, 2009; Thrush et al., 2008). The fact that the macroinvertebrate organisms could migrate freely between the paired set of reaches highlights the strength of these results. Increased effects of pesticides on freshwater macroinvertebrates have been observed with e.g. decreasing oxygen concentrations (Ferreira et al., 2010), increasing temperature (Singh and Singh, 2009) and the presence of predators (Beketov and Liess, 2006; Montoya et al., 2009). The effects of pesticides on stream biota is suggested to increase in more complex systems with several cooccurring stressors (Guy et al., 2011), and Schletterer et al. (2010) additionally indicated that the fraction of the abundance of SPEAR significantly differed between sub-samples that were collected on soft and hard substrates. Moreover, hydromorphological degradation is a key pressure on agricultural stream ecosystems that alone are likely to be a main reason that many streams do not achieve good ecological status (Friberg et al., 2009; Sandin, 2009; Wagenhoff et al., 2011). Considering the proposed threshold for good ecological quality (required in the EU Water Framework Directive) in the online SPEAR calculator (33\%SPEAR abundance) all stream sites (even uncontaminated) with degraded physical conditions were unable to fulfil the required ecological objectives in June and August.

We found that the reduced \%SPEAR abundance at stream sites characterised by homogeneous physical conditions compared with sites with heterogeneous physical conditions was primarily explained by the reduction or absence of the caddis flies Silo pallipes and Silo nigricornis (Goeridae), the stonefly Leuctra fusca (Leuctridae) and the crane fly Dicranota sp. (Limoniidae). These taxa are strongly associated with coarse substrates, turbulent flow and high oxygen concentrations (Schmera, 2004; Urbanic et al., 2005). This may suggest that the primary stressor acting on these taxa was related to physical habitat properties rather than pesticide contamination. Re-computing the \%SPEAR abundance without these taxa (\%SPEAR $R_{\text {mod }}$ abundance) removed the site-specific differences in the correlation with $\log \mathrm{mTU}_{D}$. magna. This furthermore indicates that the absence of hard substrate rather than pesticide contamination restricted these three taxa from occupying the sampling sites with homogenous and degraded physical conditions. Interactions between macroinvertebrates and substrate are well documented, and many studies congruently report that macroinvertebrate species richness, abundance and diversity increase with increasing particle size primarily facilitated by EPT taxa (Brunke et al., 2001; Miyake and Nakano, 2002). Moreover, taxa that require fast flow and coarse substrates tend to have more specific requirements for physical habitats emphasising that high habitat heterogeneity is essential if a stream site is to support a high number of macroinvertebrate species. In consequence, a considerable proportion of the macroinvertebrate taxa (primarily EPT taxa) that are classified as SPEAR may be partly or completely restricted from colonising agricultural streams due to physical habitat degradation. Furthermore, SPEAR taxa that require fast flow and coarse substrates may become increasingly sensitive to pesticide exposure in physically degraded agricultural streams due to suboptimal growth conditions (Maltby, 1999).
In June the average \%SPEAR abundance was higher for sites with heterogeneous physical properties compared to sites with homogeneous physical properties within three different contamination groups (uncontaminated sites $\left(\mathrm{mTU}_{D}\right.$. magna $<-5$ ), intermediately $\left(-5 \leq \mathrm{mTU}_{D \text {. magna }}<-3\right)$ and heavily contaminated sites $\left(\mathrm{mTU}_{D}\right.$. magna $\geq-3)$ ). However, the difference was only significant for the group of intermediately contaminated streams. For these intermediately contaminated streams, the significantly lower \%SPEAR abundance at sites with homogeneous physical conditions compared to sites with heterogeneous physical conditions was primarily governed by the abundance of SPEAR taxa belonging to Ephemeroptera, Plecoptera and Trichoptera (EPT). This suggests that the abundance of SPEAR taxa is additionally reduced beyond the effects of pesticides probably due to the additional stressor effects that are related to physical habitat degradation. However, in June the difference in \%SPEAR abundance between sites with heterogeneous and homogeneous physical conditions was significantly reduced in heavily contaminated streams compared to intermediately contaminated streams. This insinuates that the potential positive effects of heterogeneous physical stream conditions could become less important or even overruled by pesticide contamination when the toxic pressure becomes sufficiently high.

The \%SPEAR abundance before the main pesticide application season (April) was significantly correlated to the log maximum Toxic Unit for $48 \mathrm{~h}$ acute exposure to Daphnia magna (log $\mathrm{mTU}_{D}$. magna) obtained subsequently during the main pesticide application season (May and June) suggesting that sites characterised by high $\log \mathrm{mTU}_{D \text {. magna }}$ during this field campaign have probably been subject to similar levels of pesticide contamination in the previous years. Similar findings have been provided by Liess and Von der Ohe (2005) and Liess and Beketov (2011). Indeed, several studies have shown that sublethal effects of environmentally realistic duration and concentration of pesticide exposure can lead to altered behaviour and reduced competitive abilities for some stream macroinvertebrates (Fleeger et al., 2003; Liess, 2002; Rasmussen et al., 2008), and the history of intensive agricultural activities in the near-stream areas can be a better predictor for biodiversity than present land-use characteristics (Harding et al., 1998).

\section{Conclusions}

We found that the \%SPEAR abundance during the main pesticide application season was significantly lower at stream sites that were characterised by uniform and degraded physical habitats. During and immediately after the main pesticide application season even streams that were not contaminated with diffuse source pesticides - but were characterised by homogeneous and degraded physical habitats - were unable to achieve good ecological status ( $>33 \%$ SPEAR abundance). These differences were found to be primarily due to the presence or absence of macroinvertebrate taxa with specific requirements for stream habitats that are characterised by hard substrate, turbulent flow and high oxygen concentrations. Moreover, we found that the interaction between the two stressors (physical habitat degradation and diffuse source pesticide contamination) may change along a gradient in pesticide contamination.

Our results underline that the summed macroinvertebrate community response to the total amount of stress is a result of direct and indirect effects and feedback mechanisms that are defined by species biology and habitat requirements. Consequently, simple interpretation of guidelines and threshold values may underestimate responses that are triggered in the natural environment due to the interaction of multiple stressors such as pesticide contamination and physical habitat degradation. This 
study has important implications for the area of multiplicative stress in future research, risk assessment and stream management.

In addition, we suggest creating a formal macroinvertebrate sampling strategy in terms of timing of sampling and sampled habitat types to further improve the applicability and comparability of SPEAR. Moreover, the formalisation of a sampling strategy would also improve the usefulness and consistency of results if SPEAR was to be formally implemented as indicator tool for the detection and evaluation of effects of pesticide contamination within the EU.

\section{Acknowledgements}

This study was financed by the Danish Research Council (grant no. 2104-07-0035) and is part of the RISKPOINT program. We wish to thank Johnny Nielsen for assisting in the counting and identification of macroinvertebrates. Additionally, we wish to thank Henrik Stenholt, Uffe Mensberg, Dorte Nedergaard and Marlene Venø Skjærbæk and Rikke Juul Monberg for invaluable field assistance. Lastly, we wish to thank two anonymous reviewers for thorough work and helpful comments on the original manuscript.

\section{Appendix. Supplementary material}

Supplementary data associated with this article can be found, in the online version, at doi:10.1016/j.envpol.2012.01.007.

\section{References}

Baird, D.J., Baker, C.J.O., Brua, R.B., Hajibabaei, M., McNicol, K., Pascoe, T., De Zwart, D., 2011. Toward a knowledge infrastructure for traits-based ecological risk assessment. Integrated Environmental Assessment and Management 7, 209-215.

Baird, D.J., Van den Brink, P.J., 2007. Using biological traits to predict species sensitivity to toxic substances. Ecotoxicology and Environmental Safety 67, 296-301.

Beketov, M.A., Liess, M., 2006. The influence of predation on the chronic response of Artemia sp. populations to a toxicant. Journal of Applied Ecology 43, 1069-1074

Beketov, M.A., Liess, M., 2008. An indicator for effects of organic toxicants on lotic invertebrate communities: independence of confounding environmental factors over an extensive river continuum. Environmental Pollution 156, 980-987.

Brunke, M., Hoffmann, A., Pusch, M., 2001. Use of mesohabitat-specific relationships between flow velocity and river discharge to assess invertebrate minimum flow requirements. Regulated Rivers-Research \& Management 17, 667-676.

Danish Environmental Protection Agency, 2010. Pesticide Statistics, Orientering fra Miljøstyrelsen nr. 6 (In Danish), Copenhagen, Denmark.

Doledec, S., Phillips, N., Scarsbrook, M., Riley, R.H., Townsend, C.R., 2006. Comparison of structural and functional approaches to determining landuse effects on grassland stream invertebrate communities. Journal of the North American Benthological Society 25, 44-60.

Dufrêne, M., Legendre, P., 1997. Species assemblages and indicator species: the need for a flexible asymmetrical approach. Ecological Monographs 67.

Dunbar, M.J., Warren, M., Extence, C., Baker, L., Cadman, D., Mould, D.J., Hall, J., Chadd, R., 2010. Interaction between macroinvertebrates, discharge and physical habitat in upland rivers. Aquatic Conservation-Marine and Freshwater Ecosystems 20, S31-S44.

Ferreira, A.L.G., Serra, P., Soares, A., Loureiro, S., 2010. The influence of natural stressors on the toxicity of nickel to Daphnia magna. Environmental Science and Pollution Research 17, 1217-1229.

Fleeger, J.W., Carman, K.R., Nisbet, R.M., 2003. Indirect effects of contaminants in aquatic ecosystems. Science of the Total Environment 317, 207-233.

Friberg, N., Sandin, L., Pedersen, M.L., 2009. Assessing the effects of hydromorphological degradation on macroinvertebrate indicators in rivers: examples, constraints and outlook. Integrated Environmental Assessment and Management 5, 86-96.

Giller, P.S., Malmqvist, B., 1998. The Biology of Streams and Rivers, first ed. Oxford University Press, Oxford, UK.

Guy, M., Singh, L., Mineau, P., 2011. Using field data to assess the effects of pesticides on Crustacea in freshwater aquatic ecosystems and verifying the level of protection provided by water quality guidelines. Integrated Environmental Assessment and Management.

Harding, J.S., Benfield, E.F., Bolstad, P.V., Helfman, G.S., Jones, E.B.D., 1998. Stream biodiversity: the ghost of land use past. Proceedings of the National Academy of Sciences of the United States of America 95, 14843-14847.

Liess, M., 2002. Population response to toxicants is altered by intraspecific interaction. Environmental Toxicology and Chemistry 21, 138-142.
Liess, M., Beketov, M., 2011. Traits and stress: keys to identify community effects of low levels of toxicants in test systems. Ecotoxicology 20,1328-1340.

Liess, M., Brown, C.D., Dohmen, G.P., Duquesne, S., Hart, A., Heimbach, F., Kreuger, J. Lagadic, L., Maund, S., Reinert, W., Streloke, M., Tarazona, J.V., 2005. Effects of Pesticides in the Field. SETAC Press, Berlin, Germany.

Liess, M., Von der Ohe, P.C., 2005. Analyzing effects of pesticides on invertebrate communities in streams. Environmental Toxicology and Chemistry 24, 954-965.

Maltby, L., 1999. Studying stress: the importance of organism-level responses. Ecological Applications 9, 431-440.

Matthaei, C.D., Piggott, J.J., Townsend, C.R., 2010. Multiple stressors in agricultural streams: interactions among sediment addition, nutrient enrichment and water abstraction. Journal of Applied Ecology 47, 639-649.

Miyake, Y., Nakano, S., 2002. Effects of substratum stability on diversity of stream invertebrates during baseflow at two spatial scales. Freshwater Biology 47, 219-230.

Montoya, J.M., Woodward, G., Emmerson, M.C., Sole, R.V., 2009. Press perturbations and indirect effects in real food webs. Ecology 90, 2426-2433.

Paillex, A., Doledec, S., Castella, E., Merigoux, S., 2009. Large river floodplain restoration: predicting species richness and trait responses to the restoration of hydrological connectivity. Journal of Applied Ecology 46, 250-258.

Pedersen, M.L., 2009. Effects of channelisation, riparian structure and catchment area on physical habitats in small lowland streams. Fundamental and Applied Limnology 174, 89-99.

Pedersen, M.L., Friberg, N., 2009. Influence of disturbance on habitats and biological communities in lowland streams. Fundamental and Applied Limnology 174 $27-41$.

Rasmussen, J.J., Baattrup-Pedersen, A., Larsen, S.E., Kronvang, B., 2011a. Local physical habitat quality cloud the effect of predicted pesticide runoff from agricultural land in Danish streams. Journal of Environmental Monitoring 13. 943-950.

Rasmussen, J.J., Baattrup-Pedersen, A., Wiberg-Larsen, P., Kronvang, B., 2011b. Buffer strip width and agricultural pesticide contamination in Danish lowland streams: implications for stream and riparian management. Ecological Engineering 37, 1990-1997.

Rasmussen, J.J., Friberg, N., Larsen, S.E., 2008. Impact of lambda-cyhalothrin on a macroinvertebrate assemblage in outdoor experimental channels: implications for ecosystem functioning. Aquatic Toxicology 90, 228-234.

Rasmussen, J.J., Wiberg-Larsen, P., Baattrup-Pedersen, A., Kronvang, B., 2012 Impacts of pesticides and natural stressors on leaf litter decomposition in agricultural streams. Science of the Total Environment 16, 148-155.

Relyea, R., Hoverman, J., 2006. Assessing the ecology in ecotoxicology: a review and synthesis in freshwater systems. Ecology Letters 9, 1157-1171.

Rubach, M.N., Ashauer, R., Buchwalter, D.B., De Lange, H.J., Hamer, M.J. Preuss, T.G., Töpke, K., Maund, S., 2011. Framework for traits-based assessment in ecotoxicology. Integrated Environmental Assessment and Management 7, 172-186.

Rubach, M.N., Baird, D.J., Van den Brink, P.., 2010. A new method for ranking modespecific sensitivity of freshwater arthropods to insecticides and its relationship to biological traits. Environmental Toxicology and Chemistry 29, 476-487.

Sandin, L, 2009. The effects of catchment land-use, near-stream vegetation, and river hydromorphology on benthic macro invertebrate communities in a southSwedish catchment. Fundamental and Applied Limnology 174, 75-87.

Schletterer, M., Fureder, L., Kuzovlev, V.V., Beketov, M.A., 2010. Testing the coherence of several macroinvertebrate indices and environmental factors in a large lowland river system (Volga River, Russia). Ecological Indicators 10, 1083-1092.

Schmera, D., 2004. Spatial distribution and coexistence patterns of caddisfly larvae (Trichoptera) in a Hungarian stream. International Review of Hydrobiology 89, 51-57.

Schäfer, R.B., Caquet, T., Siimes, K., Mueller, R., Lagadic, L., Liess, M., 2007. Effects of pesticides on community structure and ecosystem functions in agricultural streams of three biogeographical regions in Europe. Science of the Total Environment 382, 272-285.

Schäfer, R.B., Pettigrove, V., Rose, G., Allinson, G., Wightwick, A., von der Ohe, P.C. Shimeta, J., Kuhne, R., Kefford, B., 2011. Effects of pesticides monitored with three sampling methods in 24 sites on macroinvertebrates and microorganisms. Environmental Science \& Technology 45, 1665-1672.

Singh, V., Singh, D.K., 2009. The effect of abiotic factors on the toxicity of cypermethrin against the snail Lymnaea acuminata in the control of fascioliasis. Journal of Helminthology 83, 39-45.

Statzner, B., Bis, B., Doledec, S., Usseglio-Polatera, P., 2001. Perspectives for biomonitoring at large spatial scales: a unified measure for the functional composition on invertebrate communities in European running waters. Basic and Applied Ecology 2, 73-85.

Thrush, S.F., Hewitt, J.E., Hickey, C.W., Kelly, S., 2008. Multiple stressor effects identified from species abundance distributions: interactions between urban contaminants and species habitat relationships. Journal of Experimental Marine Biology and Ecology 366, 160-168.

Tomlin, C.D.S., 2000. The Pesticide Manual, A World Compendium. Crop Protection Publications, Farnham, Surrey, UK.

Townsend, C.R., Hildrew, A.G., 1994. Species traits in relation to a habitat templet for river systems. Freshwater Biology 31, 265-275.

Townsend, C.R., Uhlmann, S.S., Matthaei, C.D., 2008. Individual and combined responses of stream ecosystems to multiple stressors. Journal of Applied Ecology 45, 1810-1819. 
Urbanic, G., Toman, M.J., Krusnik, C., 2005. Microhabitat type selection of caddisfly larvae (Insecta: Trichoptera) in a shallow lowland stream. Hydrobiologia 541, $1-12$.

von der Ohe, P.C., Prub, A., Schafer, R.B., Liess, M., de Deckere, E., Brack, W., 2007. Water quality indices across Europe - a comparison of the good ecological status of five river basins. Journal of Environmental Monitoring 9, 970-978.
Wagenhoff, A., Townsend, C.R., Phillips, N., Matthaei, C.D., 2011. Subsidy-stress and multiple-stressor effects along gradients of deposited fine sediment and dissolved nutrients in a regional set of streams and rivers. Freshwater Biology 56, 1916-1936.

Wallace, I.D., Wallace, B., Phillipson, G.N., 2003. Keys to the Case-Bearing Caddis Larvae of Britain and Ireland. Freshwater Biological Association. 